\title{
Study on Thyroid Dysfunction in Patients Attending Rama Medical Collage Hospital \& Research Centre, Kanpur (Uttar Pradesh)- A Hospital Based Study
}

\author{
Authors \\ Dr Pavan Kumar Sharma ${ }^{1}$, Dr P. B. Jain ${ }^{2}$, Dr P. Anand ${ }^{3}$, Dr I. Chaudhary ${ }^{4}$, \\ Mr S. Sharma ${ }^{5}$ \\ ${ }^{1}$ MBBS, PG Student, Department of Biochemistry; ${ }^{2}$ Professor and HOD, in Biochemistry \\ ${ }^{3,4}$ Assistant Professor, ${ }^{5}$ Tutor, Dept. of Biochemistry \\ 1,2,3,4,5 Rama Medical College Hospital \& Research Centre, Kanpur, Uttar Pradesh
}

\begin{abstract}
S
Thyroid dysfunction is defined as the altered serum thyroid stimulation hormone (TSH) level with normal or altered thyroid hormones (tri-iodothyronine- $T_{3}$ and thyroxine- $T_{4}$ ). Decreased level of circulating blood TSH with increased levels of circulating $T_{3}$ and $T_{4}$ is called overt hyperthyroidism whereas decreased level of circulating blood TSH with normal levels of circulating $T_{3}$ and $T_{4}$ is called subclinical hyperthyroidism. Increased level of circulating blood TSH with decreased levels of circulating $T_{3}$ andT $T_{4}$ is called overt hypothyroidism whereas increased level of circulating blood TSH with normal levels of circulating $T_{3}$ and $T_{4}$ is called subclinical hypothyroidism. A total 354 subjects were enrolled in this study out of these 265 were female and 89 were male. The subjects were classified according to thyroid status as euthyroidism, overt hyperthyroidism, subclinical hyperthyroidism, overt hypothyroidism and subclinical hypothyroidism by taking reference of thyroid function test. Total hypothyroidism includes overt hypothyroidism plus subclinical hypothyroidism and total hyperthyroidism represents overt hyperthyroidism plus subclinical hyperthyroidism. Overn ight fast venous blood was collected from the subjects attending RMCHRC, Kanpur. Thyroid function test panel (T3, T4 and TSH) were assayed by the Cobas e411 immunoassay analyzer and its test kits. The present study has revealed the prevalence of thyroid dysfunction typically hypothyroidism and subclinical hypothyroidism were higher in this region but the etiology of the disease remains unidentified. Moreover, the disease was preponderant in women and the people of all age-group. Our study was a hospital based study; it may not represent the whole population. But, the study has identified the burden of thyroid dysfunction in this locality and can be used as baseline data for future studies.
\end{abstract}

KEY WORDS: $T_{3}, T_{4}$ and TSH, Euthyroid and Thyroid dysfunction.

\section{INTRODUCTION}

Thyroid dysfunction is defined as the altered serum thyroid stimulation hormone (TSH) level with normal or altered thyroid hormones (tri- iodothyronine- $\mathrm{T}_{3}$ and thyroxine- $\mathrm{T}_{4}$ ). Decreased level of circulating blood TSH with increased levels of circulating $\mathrm{T}_{3}$ and $\mathrm{T}_{4}$ is called overt hyperthyroidism where as decreased level of 
circulating blood TSH with normal levels of circulating $\mathrm{T}_{3} \quad$ and $_{4}$ is called subclinical hyperthyroidism. Increased level of circulating blood TSH with decreased levels of circulating $\mathrm{T}_{3}$ andT $_{4}$ is called overt hypothyroidism whereas increased level of circulating blood TSH with normal levels of circulating $\mathrm{T}_{3}$ andT $\mathrm{T}_{4}$ is called subclinical hypothyroidism.

About 300 million people in the world are affecting from thyroid dysfunction and over half are presumed to be unaware of their condition ${ }^{1}$.According to American Association of Clinical Endocrinologists, over 27 million Americans have some form of thyroid disease with hypothyroidism being most prevalent among all thyroid dysfunctions ${ }^{2}$.It has been estimated that about 42 million people in India suffer from thyroid diseases ${ }^{1}$.Thyroid dysfunction is also called second diabetes of India.

Thyroid hormones profoundly influence the basal metabolic rate of the body. Complete lack of thyroid secretion can decrease the BMR to fall 40 to 50 per cent below normal, and extreme excesses of thyroid secretion can increase the BMR to 60 to 100 per cent above normal. Thyroid hormones play a vital role in cell differentiation during fetal development and helps in maintain thermo genic and metabolic homeostasis in the adult, so normally functioning thyroid is essential for the healthy living of an individual ${ }^{3}$.

Hypothalamus regulates pituitary gland by releasing thyrotropin releasing hormone (TRH) for the secretion of TSH and pituitary gland regulates thyroid gland by releasing TSH. Thyroid hormone secretion is controlled primarily by TSH secreted by the anterior pituitary gland.TSH stimulates thyroid gland for the secretion of thyroid hormones.TSH is regulated by the negative feedback of thyroid hormone. Thyroid hormones act directly up on anterior pituitary as well as increased level and effect of metabolites activates hypothalamus and pituitary gland. So in every altered function on hypothalamus, pituitary gland and thyroid gland leads to thyroid dysfunction $^{3,4}$.
Thyroid diseases are common clinical problems because these are associated with aging ${ }^{5}$. Moreover majority of the cases has subclinical hypothyroidism and easily pass unrecognized. Danese MD et al recommend that since hypothyroidism is very common in older woman, so it is necessary to screen asymptomatic older women for thyroid dysfunction ${ }^{6}$. The American Thyroid Association recommends that adults be screened for thyroid dysfunction by measurement of the serum TSH concentration, beginning at the age of 35 years and every 5 years thereafter ${ }^{2}$. The screening of thyroid dysfunction is strongly recommended in high risk population such as populations staying in endemic goiter prevalent areas, iodine deficiency and sufficiency disorder and autoimmune disorder ${ }^{7}$.

To access the thyroid function, thyroid function test panel (TFT) is commonly used for screening and evaluating thyroid dysfunction. The introduction of serum tri-iodothyronine (T3), thyroxin (T4) and serum thyroid stimulating hormone (TSH) Enzyme linked immuneflourescent assay (ELFA) has increased the sensitivity and specificity of thyroid function testing. The serum TSH assay has been shown to be a sensitive indicator of diminished thyroid functional reserve, since TSH levels become elevated before circulating serum thyroxin levels fall below the normal range ${ }^{8}$. Numerous studies from various countries differ in their prevalence estimates for both overt and subclinical hyper- and hypothyroidism. The differences in these studies might be due to different genetic, ethnic or environmental backgrounds of the subjects 9 . Furthermore, surveys of thyroid dysfunction in general population have been conducted mainly in western countries, and a few comparable data are available from the Asian countries like China and Japan $^{10}$.In India, various studies were done in the prevalence of thyroid dysfunction. Results were varied from place to place. The hospital based studies conducted in the coastal region of India shows $15.8 \%$ (Puducherry) and $19.6 \%$ (Cochin) of thyroid dysfunction. 
So it is necessary to conduct prevalence study in thyroid dysfunction to identify its real status in each locality. In view of above, this study has been undertaken in Rama Medical College Hospital \& Research Centre, Kanpur, Uttar Pradesh, India.

\section{MATERIAL AND METHOD}

This was a hospital based cross sectional study conducted in the Department of Biochemistry at Rama Medical College Hospital\& Research Centre, Kanpur during the period from December 2013 to January 2015. A total 354 subjects were enrolled in this study out of these 265 were female and 89 were male. The subjects were classified according to thyroid status as euthyroidism, overt hyperthyroidism, subclinical hyperthyroidism, overt hypothyroidism and subclinical hypothyroidism by taking reference of thyroid function test. Total hypothyroidism includes overt hypothyroidism plus subclinical hypothyroidism and total hyperthyroidism represents overt hyperthyroidism plus subclinical hyperthyroidism. All the patients prescribed for Total- TFT who attend outpatient department and in patient department of RMCHRC, Kanpur were including in this study.

Overnight fast venous blood was collected from the subjects attending RMCHRC, Kanpur. Thyroid function test panel (T3, T4 and TSH) were assayed by the Cobas e411 immunoassay analyzer and its test kits.

\section{Inclusion criteria:}

All clinically undiagnosed cases of thyroid dysfunction were taken for case study.

\section{Exclusion criteria:}

- Patients below the age of 20 years and previously diagnosed cases of thyroid dysfunction were not included in this study.

- Patients suffering from high grade fever, chronic illnesses (TB, HIV etc), jaundice, pregnancy, psychiatric disorders, and renal failure were excluded from study.

- A total number of 354 subjects participated in present study.

\section{Criteria of thyroid dysfunction}

The reference interval for $\mathrm{T}_{3}, \mathrm{~T}_{4}$ and $\mathrm{TSH}$ were 0.9 - $2.3 \mathrm{nmol} / \mathrm{l}, 6.0-12.0 \mathrm{nmol} / \mathrm{dl}$ and $0.25-5.0$ $\mathrm{IU} / \mathrm{ml}$ respectively. Thyroid function is considered normal (Euthyroidism) when subjects were presented with normal $\mathrm{T}_{3}, \mathrm{~T}_{4}$ and $\mathrm{TSH}$. Abnormal thyroid function was further categorized as hyperthyroid (Increased $\mathrm{T}_{3}, \mathrm{~T}_{4}$ and decreased $\mathrm{TSH}$ ), Subclinical hyperthyroid (increased $\mathrm{T}_{3}, \mathrm{~T}_{4}$ and normal TSH), hypothyroidism (decreased $\mathrm{T}_{3}, \mathrm{~T}_{4}$ and increased $\mathrm{TSH}$ ), and Subclinical hypothyroidism (decreased $\mathrm{T}_{3}$ and $\mathrm{T}_{4}$ )

\section{Statistical analysis}

Data were entered and analyzed by Microsoft Excel and Software Package for Social Sciences version 16.0 (SPSS 16.0). Data were represented as percentage, frequency and mean.

\section{RESULTS AND DISCUSSION}

Estimates of the prevalence of thyroid dysfunction depend upon methodological factors, classifications of hypothyroidism depends up on the basis of TSH reference value, and composition of the community examined by age, ethnicity, and gender. The prevalence and pattern of TDF depend on ethnic, geographic, and environmental factors including iodine intake status ${ }^{9}$.

Table 1: Distribution of patients according to the gender

\begin{tabular}{|l|c|c|}
\hline $\begin{array}{l}\text { Gender of the } \\
\text { paient }\end{array}$ & No. of cases & Percentage \\
\hline Male & 89 & $25.14 \%$ \\
\hline Female & 265 & $74.86 \%$ \\
\hline Total & 354 & $100 \%$ \\
\hline Female :male ratio $=2.97: 1$ & \\
\hline
\end{tabular}

In this study, 354 patients were enrolled for the study of thyroid dysfunction; 265 were female and 
89 were male and female: male ratio was 2.97: 1 [Table 1].

Table 2: Distribution of patients according to the age.

\begin{tabular}{|l|l|l|}
\hline Age group (years) & No. of cases & Percentae \\
\hline $20-29$ & 92 & $26 \%$ \\
\hline $30-39$ & 83 & $23.5 \%$ \\
\hline $40-49$ & 82 & $23.2 \%$ \\
\hline $50-59$ & 51 & $14.6 \%$ \\
\hline $60-69$ & 27 & $7.8 \%$ \\
\hline$>70$ & 17 & $4.9 \%$ \\
\hline Total & 354 & $100 \%$ \\
\hline
\end{tabular}

Patients above the age of 19 years were included in this study. Maximum number of patients belonged in the age group of 20-29 [Table 2]. In a similar type of hospital based study conducted by Aryal $\mathrm{M}$ et al. ${ }^{12}$ female: male ratio of the subject was 2.7:1 and maximum number of subject belonged in the age group 15-30 years.

Table 3: Distribution of patients on the basis of thyroid function

\begin{tabular}{|l|l|l|}
\hline Thyroid function & No. of cases & Percentage \\
\hline Euthyroidism & 235 & $66.38 \%$ \\
\hline Thyroid dysfunction & 119 & $33.62 \%$ \\
\hline Total & 354 & $100 \%$ \\
\hline
\end{tabular}

The prevalence of thyroid dysfunction was $33.62 \%$ in subjects attending RMCHRC, Kanpur [Table 3]. In the similar hospital based study conducted by Abraham et al. observed 15.8\% of the populations were suffering from TDF in Puduchery, India ${ }^{11}$. In another hospital based study performed by Aryal M. et al. observed 25\% of $\mathrm{TDF}^{12}$. Menon VU et al. ${ }^{15}$ had conducted a population based study in Cochin, India, they found that the prevalence of thyroid dysfunction was $19.6 \%$. In our study, we found higher prevalence of TDF in comparison to other hospital based studies.
Table 4: Distribution of patients by the subclassification of thyroid dysfunction

\begin{tabular}{|l|l|l|}
\hline Thyroid function & $\begin{array}{l}\text { No. of } \\
\text { cases }\end{array}$ & Percentage \\
\hline Euthyroidism & 235 & $66.38 \%$ \\
\hline Overt Hyperthyroidism & 22 & $6.22 \%$ \\
\hline $\begin{array}{l}\text { Subclinical } \\
\text { Hyperthyroidism }\end{array}$ & 08 & $2.26 \%$ \\
\hline Overt Hypothyroidism & 29 & $8.19 \%$ \\
\hline $\begin{array}{l}\text { Subclinical } \\
\text { Hypothyroidism }\end{array}$ & 60 & $16.96 \%$ \\
\hline Total & 354 & $100 \%$ \\
\hline
\end{tabular}

In the present study, we found $22.12 \%$ of total hypothyroidism and $8.48 \%$ of total hyperthyroidism [Table 4]. In a similar type of study, $11.5 \%$ had hypothyroidism and $1.8 \%$ had hyperthyroidism ${ }^{11}$.In another hospital based study conducted by Aryal M. et al. prevalence of hypothyroidism was $16 \%$ and hyperthyroidism was $9 \%^{12}$. Like other studies, we found the prevalence of hypothyroidism was higher than the prevalence of hyperthyroidism. It is observed that higher prevalence of hypothyroidism is observed in iodine deficient hilly areas ${ }^{12}$ as well as iodine sufficient costal areas ${ }^{11}$. Aminorroaya A et al. found the overall prevalence of hypothyroidism was $17.6 \%$ hypothyroidism. About $37.6 \%$ of hypothyroid men and women had positive antithyroperoxidase antibodies ${ }^{14}$. So, increased incidences of hypothyroidism may be because of autoimmune disorders rather than iodine deficiency.

In our study, we found, $16.96 \%, 8.18 \%, 2.62 \%$ and $6.22 \%$ of subclinical hypothyroidism, overt hypothyroidism, subclinical hyperthyroidism and overt hyperthyroidism respectively [Table 4]. In a similar study, $9.5 \%, 2 \%, 1.8 \%$ and $1.2 \%$ of subclinical hypothyroidism, overt hypothyroidism, subclinical hyperthyroidism and overt hyperthyroidism respectively ${ }^{11}$. In a population bases study,Menon UV et al. found 9.4\%, 3.9\%, $1.6 \%$ and $1.3 \%$ of subclinical hypothyroidism, overt hypothyroidism, subclinical hyperthyroidism and overt hyperthyroidism respectively ${ }^{16}$. In another population bases study, Ali $\mathrm{M}$ et al. found $6.18 \%, 1.12 \%, 0.84 \%$ and $1.12 \%$ of subclinical hypothyroidism, overt hypothyroidism, subclinical hyperthyroidism and overt hyperthyroidism respectively ${ }^{15}$.In our study, 
we found prevalence of subclinical hypothyroidism was highest among all other types of thyroid dysfunctions and similar results were observed in all other compared studies. In our study, we found subclinical hyperthyroidism was the least common thyroid disorder and similar conclusion was observed by Ali $\mathrm{M}$ et al. in their study ${ }^{15}$. Other similar studies showed contrasting result where the least common type of thyroid dysfunction was overt hyperthyroidism.

Table 5: Euthyroidism in male and female subjects

\begin{tabular}{|l|l|l|l|}
\hline Thyroid status & Female & Male & Total \\
\hline Euthyroidism & 175 & 60 & 235 \\
\hline \multicolumn{2}{|l|}{ Euthyroid female: male ratio $=\mathbf{2 . 9 1 : 1}$} \\
\hline
\end{tabular}

Table 6: Distribution of thyroid dysfunction in male and female subjects

\begin{tabular}{|l|c|c|c|}
\hline Thyroid status & Male & Female & Total \\
\hline Overt Hypothyroidism & 7 & 22 & 29 \\
\hline $\begin{array}{l}\text { Subclinical } \\
\text { Hypothyroidism }\end{array}$ & 10 & 50 & 60 \\
\hline Overt Hyperthyroidism & 7 & 15 & 22 \\
\hline $\begin{array}{l}\text { Subclinical } \\
\text { Hyperthyroidism }\end{array}$ & 2 & 6 & 8 \\
\hline Total & 26 & 93 & 119 \\
\hline Percentage & $21.85 \%$ & $78.15 \%$ & $100 \%$ \\
\hline Female: Male ratio $=\mathbf{3 . 5 7 : 1}$ & \\
\hline
\end{tabular}

In the present study, prevalence of TDF is higher in female compared to male [Table 6]. Few studies taken for the comparison with this present study were concordant with the present study which reported the subclinical hypothyroidism and overt hypothyroidism were higher in female as compared to males ${ }^{13,15,16}$. In a population based study conducted in iodine sufficient area of Iran, Aminorroaya A et al. found the overall prevalence of hypothyroidism was $4.8 \%$ in men and $12.8 \%$ in women heaving a total of $17.6 \%$ hypothyroidism $^{14 .}$ In our study, $21.85 \%$ were male and $78.15 \%$ were female among 119 TDF patients heaving higher female: male ratio of 3.57: 1 in comparison to euthyroid female: male ratio of 2.91:1 [Table 6 and 5].

Table 7: Distribution of thyroid dysfunction in different age groups

\begin{tabular}{|l|l|l|l|l|l|l|l|l|}
\hline Age & $\begin{array}{l}\text { No. } \\
\text { of } \\
\text { cases }\end{array}$ & $\begin{array}{l}\text { Euthyr } \\
\text { oidism }\end{array}$ & $\begin{array}{l}\text { Overt } \\
\text { Hypohy } \\
\text { roidism }\end{array}$ & $\begin{array}{l}\text { Suclinical } \\
\text { Hypothyro } \\
\text { idsm }\end{array}$ & $\begin{array}{l}\text { Overt } \\
\text { Hyperthyr } \\
\text { oidism }\end{array}$ & $\begin{array}{l}\text { Subclinical } \\
\text { Hyperthyro } \\
\text { idism }\end{array}$ & $\begin{array}{l}\text { Total } \\
\text { Thyroid } \\
\text { Dysfuncti } \\
\text { on }\end{array}$ & Percentage \\
\hline $20-29$ & 92 & 58 & 6 & 20 & 4 & 4 & 34 & $36.95 \%$ \\
\hline $30-39$ & 83 & 48 & 9 & 18 & 6 & 2 & 35 & $42.14 \%$ \\
\hline $40-49$ & 84 & 62 & 9 & 7 & 6 & 0 & 22 & $26.19 \%$ \\
\hline $50-59$ & 51 & 40 & 2 & 7 & 2 & 0 & 11 & $21.58 \%$ \\
\hline $60-69$ & 27 & 14 & 1 & 8 & 3 & 1 & 13 & $48.15 \%$ \\
\hline$>70$ & 17 & 13 & 2 & 0 & 1 & 1 & 4 & $23.52 \%$ \\
\hline Total & 354 & 235 & 29 & 60 & 22 & 8 & 119 & $33.62 \%$ \\
\hline
\end{tabular}

In the present study, we found highest prevalence of TDF $(48.15 \%)$ in the age group of $60-69$ years followed by $42.14 \%$ in the age group of 30-39 years. Prevalence of TDF was common in all age groups though highest value was observed in older age group. According to $\mathrm{Yu}$-shan M.et al. prevalence of subclinical and overt hypothyroidism increases with age ${ }^{16}$.In our study, we found that incidences of hypothyroidism were common in all age group.

There were few limitations of our study. The TFT test result is an excellent tool for screening new 
patients for thyroid disease but the complete thyroid panel is needed for an accurate diagnosis and assessment of thyroid function. Our study was based on total thyroid function test i.e. serum $\mathrm{T}_{3}$, $\mathrm{T}_{4}$ and $\mathrm{TSH}$ measurement. The present study could have been strengthened if free- $\mathrm{T}_{4}$, free- $\mathrm{T}_{3}$, anti-thyroperoxidase (anti-TPO), antithyroglobulin (anti $\mathrm{Tg}$ ), TSH receptor antibodies and Thyroid stimulating immunoglobulin (TSI) were included foe the further confirmation of thyroid dysfunction.

Our study was the hospital based study conducted in the limited period of time. We observed high prevalence of TDF in our study. So, further population based epidemiological studies are needed to establish the accurate prevalence and predominant etiological factors of thyroid dysfunction in this northern region of the country.

\section{CONCLUSION}

These findings suggest that the prevalence of thyroid dysfunction was higher in comparison to other similar type of hospital based studies conducted in the symptomatic patients recommended for thyroid function test. So, TFT should be used as a routine test parameter for the patients of RMCHRC, Kanpur, Uttar Pradesh, India.

The present study has revealed the prevalence of thyroid dysfunction typically hypothyroidism and subclinical hypothyroidism were higher in this region but the etiology of the disease remains unidentified. Moreover, the disease was preponderant in women and the people of all agegroup.

Our study was a hospital based study; it may not represent the whole population. But, the study has identified the burden of thyroid dysfunction in this locality and can be used as baseline data for future studies.

\section{BIBLIOGRAPHY}

1. Peter PAS eds. Epidemiology of Thyroid dysfunction-hypothyroidism hyperthyroididm. Thyroid International 2009; 2: 1-16

2. Ladenson Paul W. American thyroid association guide-lines for detection of thyroid dysfunction. Arch Intern Med. 2000; 160: 1573-1575.

3. Guyton AC, Hall JE.A Text Book of Medical Physiology. 11th edition; Elsevier publishers; 2006; pp 905-943.

4. Jameson LJ. Disorders of the Thyroid Gland. Available From: http://www.medical library.net/thyroid_therapy.html

5. Tunbridge WM, Evered DC, Hall R, Appleton D, Brewis M, Clark F, et al. The spectrum of thyroid disease in a community: the Wickham survey. ClinEndocrinol. 1977;7:481-93.

6. Danese MD, Powe NR, Swain CT, Ladenson PW. Screening for mildthyroid failure at the periodic health examinationA decision and cost effective analysis. JAMA 1996; 276: 285.

7. Staub JJ, Althaus BU, Engler $\mathrm{H}$ et al. Spectrum of sub-clinical and overt hypothyroidism: effect on thyrotro-pin, prolactin, and thyroid reserve and metabolic im-pact on peripheral target tissue. Am J Med 1992; 92: 631-642.

8. Ingbar SH, Wiwams RH. Text book of endocrinology. 7th Edn. 1985, pp 792.

9. Camargo RY, Tomimori EK, Neves SC, GS Rubio I, Galrao AL, Knobel M, etal.Thyroid and the environment: exposure to excessive nutritional iodine increases the prevalence of thyroid disorders in Sao Paulo, Brazil. Eur J Endocrinol 2008;159: 293-299.

10. Yang F, Teng W, Shan Z, Guan H, Li Y, Jin $\mathrm{Y}$, et al. Epidemiological survey on therelationship between different iodine intakes and the prevalence of hyperthyroidism.EurJEndocrinol 2002; 146: 613-618. 
11. Abraham R, Murugan S V, Pukazhvanthen $P$ and Sen $S$ K. Thyroid disorders inwomen of puducherry. Indian Journal of Clinical Biochemistry, 2009 / 24 (1) 5259.

12. AryalM,GyawaliP,RajbhandariN,AryalPPa ndey D R. A prevalence of thyroid dysfunction in Kathmandu University Hospital, Nepal. Biomedical Research 2010; 21 (4): 411-415

13. Ali M, Nouh, Ibrahim A. M. Eshnaf, and Mohamed A. Basher.Prevalence of thyroid dysfunction and its effect onserum lipid profiles in a murzok, Libya population. Thyroid Science 3(10):CLS1-6, 2008 www.ThyroidScience.com Clinical and Lab Studies.

14. Aminorroaya A, J anghorbani M, MasoudAmini M,Hovsepian S, Tabatabaei A,Fallah Z. The prevalence of thyroid dysfunction in an iodine-sufficient area in Iran.Arch Iranian Med 2009; 12 (3): $262-270262$ Archives of Iranian Medicine, Volume 12, Number 3, May 2009

15. Menon VU, Sundaram KR, Unnikrishnan AG, Jayakumar RV, Nair V, Kumar H. High prevalence of undetected thyroid disorders in an iodine sufficient adult south Indian population. J Indian Med Assoc 2009; 107:72-7.

16. Yu-shan M, Zhi-min L, Chang-xi C, Zhong-wei $\mathrm{Z}$ and Zhong-li H.Ningbo thyroid dysfunction prevalence study: a cross-sectional survey in an employee'scohort. Chinese Medical Journal 2010;123(13):1673-1678 1673

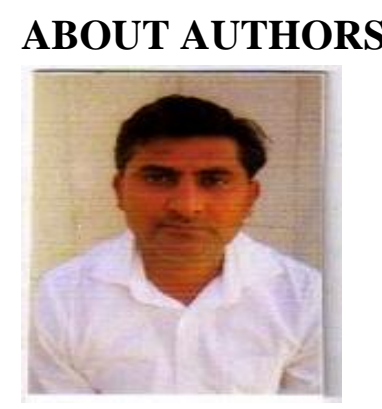

Dr Pavan Kumar Sharma, MBBS, PG Student, Department of Biochemistry, Rama Medical College Hospital \& Research Centre, Kapur, U.P., India

Email: doctorpavan1980@gmail.com 